4 Костомаров В. Русский язык на газетной полосе. M., 1970. C. 57.

5 Ермакова О., Земская Е., Розина Р. Слова, с которыми мы все встречались : Толковый словарь русского общего жаргона : ок. 450 слов / под общ. рук. Р. И. Розиной. M., 1999.

6 См.: Швейцер А. Теория перевода. Статус, проблемы, аспекты. М., 1988.

${ }^{7}$ Cм.: Nord K. Text analysis in Translation. Amsterdam, 1991.

8 Там же.

УДК 811.161.1'37:659.1

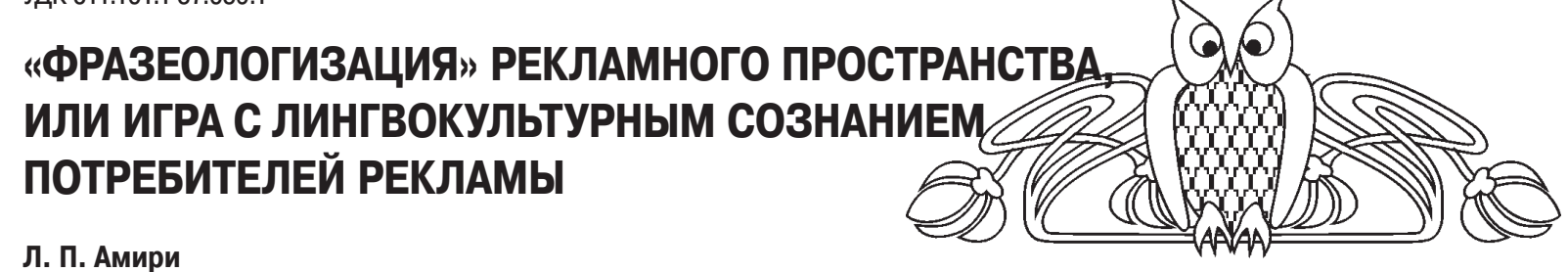

Южный федеральный университет, Ростов-на-Дону

E-mail: liudmila.amiri@gmail.com

Статья посвящена анализу фразеологических единиц в рамках рекламного дискурса. Рассматривается вопрос «обыгрывания» их внешней и внутренней формы за счет различной трансформации. Кроме варьирования компонентного состава, изменению подвергаются их синтаксическая структура и внутренняя семантика, что затрагивает проблему экспликации смысла.

Ключевые слова: язык рекламы, фразеологические единицы, трансформация смысла, прецедентное высказывание, авторский перифраз.

\section{"Phraseologisation" of Advertising Space, or a Play with the Lingvocultural Consciousness of Advertising Consumers}

\section{P. Amiri}

This article presents an analysis of phraseological units within the framework of advertising discourse. It examines the transformation of phraseological units in terms of both external and internal form. In addition to the substitution of the original components, their syntactic structure may also undergo changes, as well as their internal semantics, which directly touches upon the issue of meaning interpretation. Key words: language of advertising, phraseological units, transformation of semantics, precedent sentence, author's paraphrase.

Фразеология считается одним из самых интересных аспектов изучения языка, а фразеологические единицы (далее - ФЕ) всегда пользовались широкой популярностью в русском лингвокультурном сообществе (далее - ЛКС). Популярность использования ФЕ в разговорной речи и художественном тексте не могла обойти стороной СМИ и рекламу, что привело к большому распространению языковой игры, создаваемой через обыгрывание ФЕ, в текстах масс-медийного $^{1}$ и рекламного дискурсов ${ }^{2}$. В целом в современных исследованиях отечественной лингвистики можно отметить большой рост интереса к изучению ФЕ в различных функциональных стилях.

Актуальность исследования обусловлена необходимостью понимания когнитивных механизмов, задействованных в обыгрывании ФЕ в рекламных текстах. Предметом рассмотрения является узуальное и окказиональное использование ФЕ в создании языковой игры в рекламных текстах. Фактический материал представлен рекламными текстами (далее - РТ) независимо от их жанрового происхождения (теле-, радио-, наружная и печатная реклама). Цель статьи - вывести особенности «игрового» использования ФЕ через рассмотрение их контекстуальной реализации и способов трансформации в рамках РТ.

Для рекламистов ФЕ представляют интерес в первую очередь своей большой семантической насыщенностью. В отличие от свободных словосочетаний ФЕ обладают такими категориальными признаками, как воспроизводимость, устойчивость и соотносимость по структуре, и удерживаются в памяти реципиента как устоявшиеся единицы. Данный когнитивный аспект может быть наиболее удачно проиллюстрирован следующим текстовым сопровождением рекламного видеоролика (в скобках нами приведено предполагаемое продолжение ФЕ): Библиотека имени... (Ленина), Какие наши... (годы), Первыи блин... (комом), Семеро одного... (не ждут), Куда уехал... (иирк), О, сколько нам... (открытий чудных), Быть или... (не быть), Слезами горю... (не поможешь), Альфа и ... (Омега), Бери быка... (за рога), Мой дядя самых... (честных правил), Благими.. (намерениями вымощена дорога в ад), С лёгким... (паром), Как с гуся... (вода), Кинг... (Конг), Прыг... (скок), Пинг... (понг), Тик... (так). Быстрее, чем Вы думаете. Загрузите интернет браузер Chrome om Google (реклама поисковой системы «Google Chrome»). При просмотре 
обсуждаемого ролика продолжение ФЕ автоматически воспроизводится памятью реципиента, что доказывает тот факт, что с когнитивной точки зрения использование ФЕ не только оправданно, но и существенно увеличивает шансы РТ, практически полностью базирующегося на хорошо известных большинству представителей русского ЛКС ФЕ. Как мы видим, в вышеприведенном РТ представлены разнородные по структуре единицы (идиомы и речевые штампы, поговорки и пословицы, прецедентные имена и названия, афоризмы и крылатые выражения).

Существуют разные точки зрения по поводу того, какие языковые единицы попадают под определение ФЕ. В лингвистике сосуществуют две смежные сферы изучения ФЕ - фразеология и прецедентность. Если фразеология рассматривает аспекты сочетания и устойчивости ФЕ как единой номинативной единицы, то в аспекте рассмотрения фразеологизма как феномена прецедентности ФЕ представляют интерес не только как номинативные единицы, но и как феномен, для полного понимания которого необходимо глубокое знание как языка, так и национальной культуры русского ЛКС. Таким образом, в определении ФЕ можно выделить узкий ${ }^{3}$ и широкий ${ }^{4}$ подход. Для большого ряда исследователей этот вопрос является дискуссионным ${ }^{5}$. Согласно узкому подходу единицы фольклора (пословицы и поговорки) и фрагменты художественных текстов (крылатые выражения) выходят за границы фразеологии в сферу дискурса, так как «критерий структурной эквивалентности словосочетанию помогает отграничить фразеологизмы от слов, с одной стороны, a с другой - от устойчивых и воспроизводимых образований, по структуре представляющих собой предложения-пословицы (тише едешь - дальше будешь), поговорки (вот тебе, бабушка, и Юрьев день), крылатые выражения (счастливые часов не наблюдают) и т. п.» ${ }^{6}$. Действительно, идиомы и примыкающие к ним речевые штампы несколько выделяются в плане изучения, но нельзя отрицать того, что, будучи зафиксированными в языке, идиомы и речевые штампы также отражают языковую картину мира ЛКС. С этой точки зрения их изучение также может являться сферой исследования как фразеологии, так и прецедентности, ведь «структурно пословица является видом фразеологизма и естественно рассматривать пословицы во фразеологии - на фоне других фразеологизмов» ${ }^{7}$. И хотя пословицы и поговорки традиционно относятся к сфере фразеологии, на практике паремиология является самостоятельной научной дисциплиной со своими концептуальным аппаратом и методами исследования.

Учитывая все вышесказанное, в рамках данной работы мы придерживаемся широкого подхода к определению фразеологизма и понимаем под ФЕ «идиомы, характеризующиеся переосмыслением их лексико-грамматического состава и обладающие целостной номинативной функцией, к ним примыкают сочетания-фразеосхемы, в которых переосмыслены синтаксическое строение и определенная часть лексического состава, а остальная часть заполняется в контексте сочетаниями, в которых лексически переосмыслено только одно слово при сохранении отдельной номинативной функции за каждым из слов-компонентов, к ним близки речевые штампы, пословицы и поговорки, сформировавшиеся в фольклоре, и крылатые слова - речения афористического характера, восходящие к определенному автору или анонимному литературному источнику» ${ }^{8}$. Тем не менее следует отметить, что пословицы и поговорки, афоризмы и крылатые выражения, так или иначе обладающие конкретным (известно имя автора), относительным (известен источник, например Библия) или анонимным авторством, отличаются от идиом наличием у них категории прецедентности. Вслед за В. Е. Верещагиным и В. Г. Костомаровым, Д. Б. Гудковым мы различаем собственно фразеологизмы (идиомы и речевые штампы) и прецедентные высказывания (далее - ПВ) (пословицы и поговорки, афоризмы и крылатые выражения). ПВ всегда связаны с прецедентным текстом или прецедентной ситуацией, в то время как собственно фразеологизмы не связаны в сознании современного члена русского ЛКС с каким-либо прецедентным феноменом. Таким образом, мы понимаем под ФЕ как собственно фразеологизмы, так и ПВ, положив в основу тот факт, что все они воспринимаются реципиентами как единое смысловое целое, обладая при этом целостной номинативной функцией, ср.: «...фразеологизмы - семантически несвободные словосочетания, которые, как правило, воспроизводятся в речи в закрепленном за ними устойчивом соотношении смыслового содержания и определенного лексикограмматического состава» ${ }^{9}$. Данный подход основывается также на том, что в составе практически всех фразеологических словарей в качестве ФЕ представлены идиомы, пословицы и поговорки, крылатые выражения. Далее мы рассмотрим примеры РТ, построенных на использовании вышеобозначенных групп ФЕ.

1. Идиомы: Окна Тантроникс. Зима не за горами, она за окнами! (реклама компании «РотЯг»), Май - не за горами. Скидки товарищза Роста с Вами! (реклама группы компаний «Рост»), Зима не за горами (реклама магазина одежды «Денди для наших детей»); Распространим. Дойдет даже до жирафа (реклама газеты «Реклама-Юг»), ср.: «Дойдет и до жирафа!». В последнем случае происходят обратная актуализация и превалирование внешней формы идиомы над ее внутренней семантикой, которая обозначает тугодум, что происходит за счет изображения жирафа, сопровождающего данный РТ.

2. Речевые штампы: Абонент находится в зоне приема «Старого мельника» (реклама пива «Старый мельник»), ср.: «Абонент находится вне зоны доступа или временно отключен» (сообще- 
ние, которое прослушивают абоненты мобильной связи, если соединение с другим абонентом невозможно); Окно «под ключ» (реклама компании ООО «ИРС-Групп»); Бассейны под ключ за 7 дней (реклама фирмы «Росланд»); Спецуоперация «Teплоспасение» акиия с 7.11 по 30.11. Окно под ключ за 575 земных рублей в месяи (реклама компании «Новые окна»); Новогодние корпоративы под ключ. Тел. 207-25-27 (реклама клуба «Tesla»), ср.: под ключ, то есть начиная с фундамента и заканчивая входной дверью; При пожаре мороженое Ласунка (реклама мороженого «Ласунка»), ср.: «При пожаре звонить $01 »$.

В рекламе речевые штампы широко представлены фразеологическими кальками: Дискотека в режниме нон-стоп (реклама) ${ }^{10}$, ср.: англ. non-stop; Федерачия правовой поддержки предпринимательства Регистрачия ООО, $3 A O 280$ у.е. (BCE ВКЛЮЧЕНО!!!) (реклама фирмы «Pravo»), Faw Vita Bcё включено! (реклама автосалона «Автомир»); Новогодний корпоратив в русской сказке: все включено от 1800 рублей! Вас уже ждут в «Русском Доме». В иеену включено всё! (реклама базы отдыха «Русский дом», http:/www.russ-dom. $\mathrm{ru} / \#) ;$ Акция «Все включено»! Полноченный сайт по выгодной иене! (реклама РА «ОКЕЙ МЕДИА»); Новый Volkswagen Touareg. All inclusive (всё включено); Компания Автотрейд-АГ предлагает Вам приобрести Новый Тоиагеg по программе all inclusive (всё включено), ср.: англ. all included досл. все включено. В целом явление иноязычия во фразеологической неологии рассматривается как один из показателей успешного освоения слова и укоренения его в системе заимствующего языка ${ }^{11}$. Фразеологическая калька всё включено широко используется в качестве названий различных товаров и услуг, ср.: Обновленный тариф «Все включено L». Узнайте как стать обладателем «Золотого» иестизначного номера «Билайн» (рекламная кампания «Билайн»); ТАРИФ ВСЁ ВКЛЮЧЕНО. МОСКВА 2105 (реклама компании «МТС»); Турфирма Все Включено / ALL IN (г. Иркутск); All inclusive, или Все включено (комедия режиссера Э. Радзюкевича, 2011).

По нашему наблюдению, речевые штампы все включено, под ключ являются наиболее часто используемыми в языке РТ. Более того, как мы видим, их употребления давно вышло за рамки привычного. Изначально под ключ употреблялось относительно строительства дома или отделки квартиры, а все включено использовалось по отношению к покупке туристической путевки в отель по программе «все включено». Таким образом, рекламный дискурс расширяет словоупотребление речевых штампов, «превращая» их изначальную информативность в экспрессивность.

3. Пословицы и поговорки: Ащан - двойной удар по иенам! Один Ашан хорошо - а два лучше! (реклама гипермаркета «Ашан»), ср.: «Одна голова хорошо, а две лучше!»; Кнорр Крошка Лук. Мал да удал! (реклама кубиков «Кнорр»), ср.: «Мал золотник да дорог!», «Мал да удал»; Любишь кататься? Любишь Real? (реклама магазина «Real»), ср.: «Любишь кататься - люби и саночки возить!»; Долго вығбирать - женатылм не бывать! Окна от фирмы «Стоик» (реклама ООО «Стоик»), ср.: «Долго выбирать - женатому не бывать», «Все выбирать - женатым не бывать», «Много выбирать - женатым не бывать»; $A$ чё тянуть?! Дают - Бери! СКБ - БАНК. 100000 за 15 минут, кредит на потребительские нужды (реклама «СКБ-Банка»), ср.: «Дают - бери, бьют беги!».

Наряду с русскими пословицами и поговорками рекламисты прибегают к использованию иноязычных, например английских, пословиц и поговорок (которые, скорее всего, воспринимаются как «исконно русские»): Мой дом - моя мебель (реклама ателье мебели «Ника Юг»), ср.: рус. «Мой дом - моя крепость» - англ. «А man's home is his castle», "An Englishman's home is his castle»; Здесь вы сами можете выковать свою монету. Куй монету, пока горячо! Стань кузнецом своего счастья! (реклама туристического аттракциона в г. Санкт-Петербурге), ср.: 1. «Куй железо, пока горячо!», 2. Англ. пословица «Everyone is the blacksmith of their own happiness» - «Каждый кузнец своего счастья»; Путь к сердиу мужчины лежит через... (далее в рекламном постере присутствует изображение кухни) (реклама магазина «Мебельный центр»), ср.: рус. «Путь к сердцу мужчины лежит через желудок» - англ. «Тhe way to a man's heart is through his stomach».

4. Афоризмы и крылатые выражения: Хлебной... И зрелищ! (реклама водки «Хлебная»); Хлеба и зрелища на выставке Юга России 2006 (реклама сельскохозяйственной выставки), ср.: «Хлеба и зрелищ!» (строка из произведения Ювенала «Критик»); Открылся новыц бутик дверей РИМ. Все двери ведут в Рим (Выбирай. 2003. № 14) ${ }^{12}$, ср.: «Все дороги ведут в Рим»; Пиво без «Кириешек» - деньги на ветер! (реклама сухариков «Кириешки МАХ»), ср.: «Пиво без водки - деньги на ветер»; Big Bon приходт во время еды (реклама лапши «Big Bon»), ср.: «Аппетит приходит во время еды»; Делайте деньги не отходя от монитора (реклама курсов обучения биржевой торговле «ForexClub»), «Куйте скидки, не отходя от кассы! Строймаркет (Рекламный щит. 2009)» ${ }^{13}$, ср.: «Считайте деньги, не отходя от кассы»; Говорит и показывает «Мегафон» (реклама мобильной компании), ср.: «Говорит и показывает Москва»; Скидки товарищяа Роста с Вами! Покупатели окон всех стран - присоединяйтесь! (реклама группы компаний «Рост»), ср.: «Пролетарии всех стран, соединяйтесь!».

Отдельной группой среди крылатых выражений и афоризмов выступают библейские фразеологизмы, которые образуют общее поле фразеологизмов в культурах христианского мира: Время покупать окна! (реклама компании «Стройкомплекс плюс»); Время собирать бабки! (рекла- 
ма магазина электронной техники «Эльдорадо»), ср.: «Время собирать камни!»; Каждой паре ... по Полету! Летайте от 300 руб. (реклама «Skyexpress»); Каждой паре по паре! При покупке 2-х предметов встройки подарок! (реклама компании «Soft корпорация»), ср.: «Каждой твари по паре»; Бонбекон знают все: не хлебом единым жив человек (реклама продукции «Бонбекон»), ср.: «Не хлебом единым жив человек»; Блог в помощь! (реклама сайта «Sensator.ru»), ср.: «Бог в помощь!»; Подпишись на Комсомолку, с ней найдешь в стогу иголку! (реклама подписки на газету «Комсомольская правда»), ср.: «найти иголку в стоге сена».

В РТ ФЕ могут быть использованы в своей оригинальной форме, а могут претерпевать как частичную, так и полную трансформацию: полное сохранение структуры и компонентного состава (Старый друг - лучше новых двух! (реклама интернет-услуг компании «Comstar»), Fairy. Cmapый друг лучше новых двух (реклама моющего средства «Fairy»), ср.: «Старый друг лучше новых двух»); частичное сохранение компонентного состава: (Связь оправдывает средства (реклама компании «Евросеть»), ср: «Цель оправдывает средства»); частичное сохранение или изменение структуры (Весна красна диванами (реклама салона мебели), ср.: «Не красна изба углами, а красна пирогами»). При сохранении компонентного состава и грамматической структуры ФЕ изменение или дополнение внутренней семантики ФЕ может происходить за счет расширения компонентного состава ФЕ («С сибирским размахом, с питерским шиком» (реклама пива) ${ }^{14}$, ср.: с размахом - здесь с широким размахом) и за счет усечения компонентного состава ФЕ (Человек красит место. $A$ чем? (реклама краски «Profi avi»), ср.: «Не место красит человека, а человек красит место»). В последнем примере перефразирование ФЕ также во многом реализуется за счет последующего вопросительного предложения.

Расширение внутренней семантики ФЕ может также происходить за счет предложения, выступающего в роли комментария, вносящего свою «корректировку» в смысл всего РТ: Утро добрым не бывает! Завтрак в Макдональдс помогает! (реклама «Макдональдс»), ср.: «Утро добрым не бывает»; «Не красна изба углами, а красна пирогами! Уж что-что, а пироги у нас знатные. Кафе «Масленица» (Выбирай. 2005. № 15) ${ }^{15}$. При частичном сохранении компонентного состава и грамматической структуры «корректировка» семантики ФЕ может происходить за счет замены сразу целого ряда компонентов: В моем мобильном все должно быть прекрасно. Сделаем! Зайди на наш WAP-caŭm! (реклама компании «Мегафон»), ср.: «В человеке все должно быть прекрасно».

Использование ФЕ чаще всего имеет место в измененной форме, а оригинальный текст подвергается сокращению и разнообразной деформации, так как «экспрессивный эффект значительно усиливается в результате разного рода транс- формаций, которые происходят в прецедентных феноменах по воле автора» ${ }^{16}$. Можно выделить несколько уровней трансформации ФЕ в РТ: 1) лексическая трансформация (изменение компонентного состава ФЕ); 2) грамматико-синтаксическая трансформация (изменение грамматической и синтаксической структуры ФЕ); 3 ) семантическая трансформация. Далее мы рассмотрим примеры этой трансформации.

1. Лексическая трансформация может осуществляться: за счет замены одного слова или словосочетания (А мама сказала: «Иммунитета много не бывает!» (реклама продукта «Aktivia»), ср.: «Денег много не бывает!»; Держи пиво в холоде, а ноги в тепле (реклама пива «Бочкарев»), ср.: «Держи голову в холоде, а ноги в тепле»), нескольких слов (Толстому ломтику и рот радуется (реклама продукции «Царицынские колбасы»), ср.: «Большому куску и рот радуется!»). Иногда ФЕ переживает полную замену компонентного состава, но сохраняет свою грамматическую структуру, которая обладает апелляцией к исходной ФЕ: Окна за окна! (реклама фабрики окон), ср.: «Око за око!».

2. Грамматико-синтаксическая трансформация: Мы сделаем из слона муху (реклама «АльфаБанк»), ср.: «делать из мухи слона» - перен. раздувать проблему из ничего. Следует отметить, что за счет изменения грамматической структуры ФЕ снимается негативная коннотация ФЕ: Масло кашей не испортишь (реклама сливочного масла), ср.: «Кашу маслом не испортишь». В данных примерах субъект и объект поменяли местами. На базе одной ФЕ может иметь место совмещение разноуровневой трансформации: Кто раньше встал, тот первый подписался! (реклама подписки на газету «Южная столица»), ср.: «Кто рано встает, тому Бог подает!». Как мы видим, ФЕ претерпевает несколько видов трансформации одновременно: лексическую и грамматическую. А любая трансформация, как лексическая, так и грамматико-синтаксическая, непосредственно влечет за собой частичное или полное изменение внутренней семантики ФЕ.

3. Семантическая трансформация, или авторский перифраз (здесь перефразирование $\Phi E)$, может быть частичной и осуществляться с сохранением основной идеи ФЕ: Два подарка лучше, чем один (реклама компании «Билайн»), ср.: «Одна голова хорошо, а две лучше», или с полным переосмыслением ФЕ: Красота не требует жертв. Красота требует ухода (реклама косметической продукции «Черный жемчуг»), ср.: «Красота требует жертв». В роли вспомогательного средства семантической трансформации ФЕ может выступать такое графическое средство, как многоточие, которое, фиксируя паузу, предвосхищает использование приема обманутого ожидания и активизирует внедрение в текст нового смысла: Важен не подарок... а хороший подарок! (реклама сайта покупки подарков http://abc.ru), cp.: «Важен не подарок, а внимание»; Не надо изобретать ... 
Velas вся музыка для авто (реклама фирмы «Velas»), ср.: «Не надо изобретать велосипед».

Самым интересным способом семантической трансформации ФЕ мы считаем авторский перифраз, когда в зависимости от той или иной рекламной идеи ФЕ подвергается полной деформации и в РТ имеет место авторское «возрождение» внутренней семантики ФЕ: ОСТАЛОСЬ РОДИТЬ СЫНА. Дом - в кредит, дерево - в подарок. Ипотека от 10\% (реклама «Абсолютбанка»), ср.: «Каждый мужчина в своей жизни должен родить сына, построить дом и посадить дерево»; Серебро дороже золота (реклама зубной пасты), ср.: «Слово - серебро, а молчание - золото»; Всему молоку молоко! (реклама молока «Домик в деревне»), ср.: «Хлеб всему голова»; ASUS P505 - Мобильность у вас в руке (реклама смартфона), ср.: «Лучше синица в руке, чем журавль в небе».

Проблема экспликации актуального значения ФЕ является очень важной для правильного «сотворения» любого РТ. На его дешифровку у реципиента должен уходить минимум времени, в обратном случае при попытке осмысления РТ реципиентом произойдет коммуникативная неудача. По степени эксплицитности выделяют: 1) идиомы «с живой внутренней формой, мотивирующей актуальное значение (выражений типа ловить рыбку в мутной воде, выйти сухим из воды, вести двойную игру), информация, вводимая актуальным значением фразеологизма, является не явной, а скрытой $<\ldots>$. Явной частью оказывается именно внутренняя форма» ${ }^{17}:$ ХРАНИТЕ ДЕНБГИ В КУБЫШКЕ! ВКЛАД «КУБЫШКА» - реальный процент, стабильный доход! (реклама вклада «Кубышка» Юго-Западного банка), ср.: «держать деньги в кубышке»; 2) идиомы, внутренняя форма которых не осознается современным носителем русского языка. «Значения идиом не видно ни зги ( $\approx$ 'ничего не видно'), испокон веков/веку/века ( $\approx$ 'всегда'), не хухры-мухры ( $\approx$ 'что-то, что нельзя рассматривать как неважное') более эксплицитны, поскольку “не подавляются" семантикой легко осмысляемой внутренней формы. В таких идиомах актуальное значение вполне может квалифицироваться как эксплицитный способ передачи информации» ${ }^{18}$. Так как для рекламистов крайне важно задействовать как можно большее количество планов выражения, чаще используются именно ФЕ с «живой внутренней формой»: Искусство выстего трикотажа (реклама магазина «Пеликан»), ср.: «искусство высшего пилотажа», то есть изделия фирмы «Пеликан» - это не просто изделия из трикотажа, а произведения искусства.

В следующем виде семантической трансформации прибегают к реализации приема обманутого ожидания через активизацию буквального значения компонентов ФЕ с имплицитным значением: Отдай последнюю рубашку и купи новую в Savage (реклама магазина «Savage»), ср. «отдать последнюю рубашку» - об отзывчивом человеке, готовом поделиться с кем-либо тем единственным, значительным, что только у него и осталось; Когда простуда берет за горло, примите Strepsils (реклама сосательных леденцов «Strepsils»), ср.: «брать за горло» - принуждать кого-либо к чему-либо, заставлять поступать определённым образом. Сочетание обыгрывания речевой неоднозначности с приемом обманутого ожидания приводит к буквализации значения

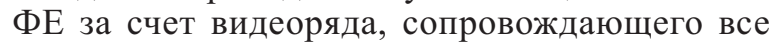
вышеприведенные тексты. Так, в первом случае мы видим молодого человека, срывающего с себя рубашку, во втором - человека, в приступе боли приложившего руки к горлу. В подобных примерах окказиональные фразеологизмы создаются на базе узуальных. Однако в рекламе также встречаются примеры создания фразеологических неологизмов через буквализацию значения лексических компонентов: Твой банк в кармане (реклама кредитных карт банка «Русский стандарт»), ср.: «в кармане» - здесь все уже решено в чью-то пользу. Текст сопровождается изображением кармана, из которого торчит банковская карта.

В основе семантической трансформации ФЕ может также лежать обыгрывание прецедентной ситуации, то есть происходит наложение семантики прецедентной ситуации (наступление года Свиньи по китайскому календарю) на ПВ: Новогодняя интрига. Ход свиньей! (реклама магазина «Красный куб»), ср.: «ход конем».

Рассмотрение способов трансформации ФЕ доказывает, что, независимо от того является ли цитирование ФЕ полным или трансформированным, любая ФЕ приобретает новый смысл за счет изменения вербального и ситуативного контекста ФЕ, кроме того, «в результате столкновения с новым языковым контекстом происходит сдвиг смысловой и, что важно, стилистической направленности цитаты, которая семантически подчиняется контексту» 19 .

Для когнитивно-прагматической оценки эффективности использования ФЕ в рекламном дискурсе важным является обыгрывание ее положительной коннотации: Маленький да удаленький. Компьютер для работы вне дома и офиса (реклама магазина «Computer-city»), ср.: «Мал золотник да дорог!», «Мал да удал». Положительная мотивация заключается в том, что ФЕ хорошо знакома реципиенту и соответствует смыслу РТ. Однако переосмысление семантики ФЕ также может происходить за счет снятия исходной негативной коннотации через замену компонентного состава ФЕ: От подарка не убежсишь (реклама мобильной связи «Билайн»), ср.: «От судьбы не уйдешь», то есть за счет лексической трансформации через внедрение нового компонента подарок. Крошки Sorti выведут грязь на чистую воду (реклама моющего средства «Sorti»), ср.: «выводить на чистую воду». Снятие негативной коннотации ФЕ «выводить на чистую воду» происходит за счет наличия видеоряда с изображением персонажей (крошек Sorti), вычищающих пятна грязи, то есть 
за счет буквализации значения ФЕ. Актуализация значения ФЕ может также осуществляться через использование его прямого значения: Болей до последней капли! (реклама пива «Calsberg»), ср.: «Пей до дна!». Обыгрывание внутренней семантики фразеологизма «до дна» происходит через использование его прямого значения до последней капли; Выжми все соки из своей соковыжсималки (реклама соковыжималки) $)^{20}$, ср.: «выжать все соки из кого-либо». Речевая неоднозначность РТ создается и через буквализацию фразеологизма, что также позволяет снять его негативную коннотацию. Как мы видим, рассматриваемые примеры РТ приобретают определенную афористичность непосредственно за счет передачи внутренней семантики ФЕ, так как на когнитивном уровне реципиент подсознательно воспринимает внутреннюю семантику ФЕ и РТ имеет больше шансов на успех именно благодаря тому, что апеллирует к лингвокультуре реципиента.

С когнитивно-прагматической оценки рекламного текста обыгрывание ФЕ может быть как уместным (Евро рубль бережет! Евро по цене доллара (реклама автомобиля «Ford»), Евро рубль бережет. Вы экономите 4 рубля на каждом евро при покупке автомобиля Ford (реклама $3 \mathrm{AO}$ «Юнион»), ср.: «Копейка рубль бережет» - пример интересен тем, что имеет место игра с заимствованной и исконно русской лексикой: словами евро и рубль; использование пословицы при создании данного рекламного текста не только уместно, так и оправданно мотивировано - покупая автомобиль «Ford», покупатель платит за евро по цене доллара, что помогает ему сэкономить деньги), так и неуместным: Колдрекс. Семь бед-один ответ (реклама лекарства «Колдрекс», построенная на дословном использовании пословицы: «Семь бед - один ответ»). Цель данного текста - вызвать у реципиента положительную мотивацию. Смысл рекламного текста заключается в том, что лекарство «Колдрекс» - это лечение от всех болезней. Но пословица «Семь бед - один ответ» имеет другое значение - «Двум смертям не бывать, а одной не миновать». Следовательно, истинный смысл данного рекламного текста - «Двум смертям не бывать, а одной не миновать» - сильно отличается от того, что хотел сказать рекламодатель. Игра с внутренней формой пословицы не всегда может быть эффективной, а само использование ФЕ в рассматриваемом случае с точки зрения прагматики является уловкой.

Главное отличие использования ФЕ в РТ от художественной и разговорной речи заключается в том, что авторы РТ не боятся, что изменение таких параметров, как фиксированный порядок и компонентный состав, может привести к разрушению ФЕ. Более того, в ряде известных нам примеров обыгрывание внутренней семантики ФЕ может преобладать над его внешней формой. В таких случаях мы имеем дело с передачей общего смысла ФЕ через абсолютно другие лексические единицы: Тайдом стирать, детей не ругать (реклама стирального порошка «Тайд»), ср.: «В лес ходить, волков не бояться»; Для настоящего коммерсанта 15 лет - не срок (реклама газеты «Коммерсант»), ср.: «Для бешеной кобылы сто вёрст - не крюк», «Для бешеной собаки семь вёрст не крюк», «Бешеному кобелю семь верст не крюк».

Об исключительной популярности ФЕ свидетельствует ставший давно привычным факт тиражируемости одной и той же ФЕ в рекламе разных товаров: Peugeot Любовь с первого взгляда (реклама официального дилера «Пежо Орбита»), Это была любовь с первой ложки!, Любовь с первой ложки (реклама бульонных кубиков «Gallina Blanca»), Новая Škoda Fabia. Любовь с первой поездки (реклама автомобиля), ср.: «Любовь с первого взгляда»; Береги здоровье смолоду! (реклама матрасов Дикуля), Берегите слух смолоду (реклама комплекса антиоксидантов, витаминов и микроэлементов «АКУСТИК» для профилактики снижения слуха), Береги свой Zyxel смолоду! (реклама модема «Zyxel»); ср.: «Береги честь смолоду, а здоровье под старость», «Береги платье снову, а честь смолоду»; Подготовься к зиме осенью! Комплект зимних шин в подарок! При покупке автомобиля KIA, Suzuki, Mitsubishi (реклама автосалона «Модус»), Готовь шубу летом! (реклама выставки-продажи в ДК «Роствертол»), Готовь сани летом, теплицу - зимой. Проектирование и изготовление теплиц по индивидуальным заказам. 8(925)546-88-95, 8(495)740-83-16 (реклама компании «Фазенда»), Готовь сани летом... и компьютер тоже. Летние скидки в "Доме компьютеров» (Челяба. 2004. № 22)» ${ }^{21}$, ср.: «Готовь сани летом, а телегу - зимой!».

Проведенное нами исследование доказывает, что использование ФЕ придает РТ яркую стилистическую окраску и новизну восприятия за счет «базового знакомства» $Ф Е$ - адресата и адресанта. Такая эффективность языковой игры объясняется срабатыванием механизма актуализации общего смысла ФЕ, базирующегося на культурной памяти ЛКС.

Непременным условием при выборе ФЕ для создания РТ во избежание коммуникативной неудачи должна быть ее известность абсолютному большинству представителей русского ЛКС. Широкое употребление ФЕ в РТ объясняется большой возможностью их узнаваемости как в частичном, так и полностью трансформированном виде при опоре реципиента на фоновые знания.

Частое использование ФЕ в трансформированном виде объясняется тем, что оно позволяет, с одной стороны, сохранить узнаваемость $Ф Е$, а с другой - придать ФЕ необходимое контекстуальное значение для продвижения рекламируемых товара или услуги. В РТ встречается трансформация $\Phi \mathrm{E}$, основанная как на изменении грамматической структуры, так и на варьировании внутренней семантики ФЕ. 
Тиражируемость языковой игры с ФЕ, способы трансформации ФЕ, ставшие привычными для рекламного дискурса, свидетельствуют о создании единого игрового пространства внутри рекламного дискурса или наложении полей игрового и рекламного дискурсов.

Количественный анализ рекламных примеров, имеющихся в нашей картотеке, показал, что наиболее частотным является использование пословиц и поговорок, на втором месте находятся крылатые выражения и афоризмы, на третьем идиомы, а на последнем - речевые штампы. Это можно объяснить тем, что речевые штампы или речевые клише не всегда можно выделить как относящиеся к культурной памяти и они редко фиксируются в специальных словарях. Конечно, за исключением тех случаев, когда они становятся «олицетворением» эпохи.

\section{Примечания}

1 Подробнее об этом см.: Зеленов А. Фразеологизм в роли газетного заголовка : автореф. дис. ... канд. филол. наук. Великий Новгород, 2009 ; Ильясова С., Амири Л. Языковая игра в коммуникативном пространстве СМИ и рекламы. М., 2009 ; Саютина Н. Трансформация фразеологических единиц в газетной публицистике : жанровая специфика // Изв. Сарат. ун-та. Новая серия. Сер.: Филология. Журналистика. 2011. № 4. С. 29-33.

2 Подробнее об этом см.: Амири Л. Языковая игра в российской и американской рекламе: дис. ... канд. филол. наук. Ростов н/Д, 2007 ; Ильясова С., Амири Л. Указ. соч.; Гирняк Е. Идиоматичность рекламного текста (на материале русской и китайской рекламы) // Вестн. Пермск. ун-та. 2011. Российская и зарубежная филология. Вып. 1(13) С. 32-38; Казанцев А. Фразеологизмы в рекламных текстах челябинских СМИ // Вестн. Челяб. гос. ун-та. 2009. № 43(181). Филология. Искусствоведение. Вып. 39. С. 69-72.

3 Подробнее об этом см.: Верещагин Е., Костомаров В. Язык и культура. Лингвострановедение в преподавании русского языка как иностранного. 3-е изд., перераб. и доп. М., 1983 ; Гудков Д. Теория и практика межкультурной коммуникации. М., 2003.

4 Подробнее об этом см.: Дубичинский В. Лексикография русского языка : учеб. пособие. М., 2008 ; Лингвистический энциклопедический словарь / под ред. В. Н. Ярцевой. М., 1990.

5 Подробнее об этом см.: Макаров В. Особенности реализации текстообразующей функции фразеологизмов и прецедентных феноменов // Вестн. Новгород. гос. ун-та. 2010. № 57. С. 60-62; Он же. Субстантивные фразеологизмы и прецедентные имена // Вестн. Новгород. гос. ун-та. 2009. № 51. С. 73-76.

6 Гутовская М. Категориальные и факультативные признаки фразеологизма // Язык - текст - дискурс : традиции и новаторство : материалы междунар. науч. конф. : в 2 ч. Самара, 2009. Ч. 1. С. 172.

7 Баранов А., Добровольский О. Пословицы как разряд фразеологизмов (новый подход к старой категории) // Русский язык : исторические судьбы и современность : IV Международный конгресс исследователей русского языка : Труды и материалы. M., 2010. С. 736.

8 Лингвистический энциклопедический словарь. С. 559.

9 Дубичинский В. Указ. соч. С. 298-299.

10 Маринова Е. Иноязычное слово как компонент новых фразеологических единиц // Филология. Искусствоведение. Вестн. Нижегород. ун-та. 2008. № 4. С. 248.

11 Там же. С. 246-251.

12 Казанцев А. Указ. соч. С. 71.

13 Там же.

14 Гирняк Е. Указ. соч. С. 35.

15 Казанцев А. Указ. соч. С. 70.

16 Ильясова С., Амири Л. Указ. соч. С. 226-227.

17 Баранов А. Лингвистическая экспертиза текста : теория и практика : учеб. пособие. 2-е изд. М., 2009. С. 66-67.

18 Там же. С. 67.

19 Гузь М. Интертекстуальные связи базисного текста и текста пародии (на материале немецкой прозаической пародии) : дис. ... канд. филол. наук. СПб., 1997. С. 105.

20 Гирняк Е. Указ. соч. С. 34.

21 Казанцев А. Указ. соч. С. 71.

УДК 340.113.1 - Правовой язык. Правовой стиль

\section{ОПИСАТЕЛЬНАЯ ЧАСТЬ СУДЕБНОГО РЕШЕНИЯ: СТИЛИСТИЧЕСКАЯ МОДЕЛЬ И ЕЕ РЕАЛИЗАЦИЯ}

\section{О. В. Никитина}

Саратовская государственная юридическая академия

E-mail: wetlinaow@mail.ru

В статье рассматриваются вопросы стилистического оформления описательной части судебного решения. Особое внимание уделено абзацному членению текста, употреблению отглагольных существительных, местоимений, союза также.

Ключевые слова: судебное решение, описательная часть, отглагольные существительные, местоимение, союз также, абзацное членение.

\section{Descriptive Part of the Judicial Decision: Stylistic Model and its Realization (Stylistic Features)}

\section{V. Nikitina}

The article studies stylistic peculiarities of the descriptive part of the judicial decision. Particular attention is paid to such issues as 